\title{
EL CONFLICTO EN TERRITORIO MAPUCHE EN EL AÑO DEL ESTALLIDO SOCIAL
}

\author{
Nicolás Rojas Pedemonte ${ }^{1}$, \\ Constanza Lobos ${ }^{2}$ \\ David Soto $\mathrm{SJ}^{3}$
}

El conflicto es constitutivo de toda sociedad y la violencia es el origen histórico de los Estados nacionales. Sin embargo, en diversas latitudes del mundo, y en nuestro continente, los modelos de democracia han logrado consolidar mecanismos institucionales para canalizar buena parte de la conflictividad social. En el territorio chileno y, en especial en territorio mapuche, se ha hecho evidente en las últimas dos décadas la incapacidad de la institucionalidad democrática chilena de sustentar el orden y la convivencia sin vulnerar los derechos humanos en la sistemática represión de la protesta social. En definitiva, la ilegitimidad social del modelo heredado de la dictadura cívico-militar redunda en un ejercicio abusivo del poder y sin autoridad. Toda sociedad moderna enfrenta el desafío de articular la solidaridad, la colaboración y la pacífica convivencia entre actores y territorios diversos, pero el Estado chileno ha reprobado reincidentemente esta tarea. La sostenida escalada del conflicto en territorio mapuche y el reciente Estallido Social no han hecho más que confirmar que el Estado ha fracasado en esta crucial tarea, desestimando, por ejemplo, sucesivas reconvenciones y recomendaciones internacionales en materia indígena.

Si bien toda sociedad desarrolla un umbral de tolerancia a determinadas violencias e injusticias, el Pueblo Mapuche y el pueblo chileno han manifestado con suficiente claridad y disrupción que este límite se ha 
superado. Solo la clase política chilena y la élite social parecen tolerar y justificar los elevados costos humanos que ha acarreado la prolongación de un modelo profundamente violento, abusivo y socioambientalmente insostenible. Es precisamente esta brecha de ilegitimidad política cubierta con represión y violencias, la que aborda este nuevo número de nuestra colección anual inaugurada hace ya casi un año con el libro "De la Operación Huracán al Comando Jungla". Esta colección hoy ofrece un segundo número de análisis multidimensional de un conflicto con profundas raíces políticas e históricas.

Mientras aquella primera publicación abordó el desarrollo de un año 2018 marcado por los montajes y el asesinato de Camilo Catrillanca, hoy "La Resistencia Mapuche y el Estallido Social en Chile" cubre en sus distintos capítulos los principales procesos e hitos del año 2019, destacando entre ellos, aquel ciclo de movilizaciones conocido como "Primavera Chilena", "Revuelta", "Estallido" y "El Despertar de Chile”, entre otros. Esta nueva publicación pretende abarcar todo el último año, pero ineludiblemente presta especial atención en este ciclo de contienda que, por un lado, elevó a escala nacional las demandas por dignidad y justicia y, por otro, amplificó la represión policial y las violaciones a los derechos humanos por décadas institucionalizadas en territorio mapuche. El año 2019 será recordado como parteaguas entre un Chile, aparentemente estable, que gestionaba específicos conflictos locales o sectoriales, a un país movilizado, con su institucionalidad desbordada y atravesado por la represión y la violencia colectiva en sus principales ciudades. Dado este escenario, la presente publicación estudia la conflictividad, las políticas y las principales coyunturas del año reciente respecto a la causa mapuche, pero también analiza con detención lo específico del ciclo del Estallido. Por una parte, se estudia y evalúa el impacto y la proyección política del Estallido y, por otra, su vínculo con la lucha mapuche, ya sea en relación con la dimensión "mapuche" del Estallido, como también con respecto al alcance e impacto real del Estallido en la contienda, las comunidades y organizaciones histórica de Wallmapu.

En las calles de las principales ciudades del territorio ondearon numerosas banderas durante el Estallido, pero destacaron cuatro banderas como las más icónicas y recurrentes: una bandera chilena negra con ribetes blancos, y las tres banderas indígenas: la Wiphala altiplánica, la tradicional Wünelfe mapuche y, por sobre todo, la contemporánea Wenufoye, con su carga simbólica y política vinculada al movimiento social mapuche.

Así, esta nueva publicación analiza las intersecciones entre la resistencia mapuche y el "despertar de Chile". Las autoras y los autores, mapuche y no mapuche, que se hacen parte de este número aportan diversas claves de análisis, para entender las conexiones entre la resistencia mapuche y el Estallido, pero también las incógnitas y particularidades que cada lucha particular supone.

Nuevamente hemos convocado a expertos y expertas en temáticas relacionadas con la 
causa mapuche y el conflicto territorial, con el objetivo de brindar un análisis lo más completo y pormenorizado de lo sucedido durante el año pasado. El primero de los capítulos indaga en la política indígena. Por ende, en este apartado se revisan las medidas tomadas desde el Gobierno e implementadas en la agenda del año 2019, de las que se desprenden la continuidad de la militarización en territorio mapuche, la suspensión del proceso de Consulta Indígena y el permanente desencuentro entre los aparatos estatales y las comunidades. Posteriormente, el segundo capítulo analiza la dinámica de la protesta mapuche, su distribución territorial y sus principales ciclos e hitos, preguntándose en particular sobre el alcance y la expresión que tuvo el Estallido en territorio mapuche. El capítulo tercero aborda la participación política e institucional mapuche, pero -a diferencia del primero- desde el análisis de las acciones que el propio Pueblo Mapuche ha llevado a cabo durante el año 2019, evaluando el despliegue institucional de las demandas mapuche en distintos ámbitos y espacios de poder político y estatal. Especial atención se presta al fra- caso del proceso de Consulta Indígena y la contienda institucional durante el desarrollo del Estallido.

El cuarto artículo aborda la vulneración de los derechos humanos en el contexto de represión de la protesta social mapuche y, sobre todo, en el marco del Estallido. El siguiente capítulo, estrechamente relacionado con el anterior, expone cómo el sistema judicial termina siendo una arena de disputa política. A partir de la revisión de condenas y formalizaciones, los autores señalan que la contienda desatada en octubre deja en evidencia que la pugna legal se trata de un tablero desnivelado, donde las iniciativas de "judicialización represiva de la protesta" serían más eficaces que las de "protección" y defensa, dados los recursos y esfuerzos que el propio Estado allí deposita. Se describe en este contexto, el desamparo histórico de las comunidades mapuches, y hoy, también, el del movimiento popular chileno, frente a un sistema judicial, deviene en un instrumento estatal para el ejercicio de la represión a la ciudadanía.

El sexto apartado aborda y evalúa las diversas vinculaciones entre el movimiento mapuche y la "Primavera chilena". A pesar de que difieren en sus antecedentes históricos - pues el movimiento mapuche es de más larga data que este nuevo movimiento popular ciudadano- el autor deja en claro que existen importantes elementos comunes, tales como el ejercicio del poder desde abajo, una respuesta represiva desde las entidades estatales y el fuerte cuestionamiento a las lógicas coercitivas, al poder político, a las figuras políticas y al modelo neoliberal en general. Consecutivamente, el capítulo 7, sobre derecho internacional, revisa la aplicación e implementación de los derechos colectivos y territoriales del Pueblo Mapuche en Chile. Así, se revisan la evolución de los estándares interamericanos en la materia, para luego dar paso a la revisión de las formas en que organismos internacionales se han pronunciado frente al cumplimiento de los compromisos internacionales 
contraídos por el Estado chileno en relación a la protección de derechos humanos e indígenas. Por último, se destacan las enormes brechas del marco normativo chileno y los estándares internacionales, con profundos déficits en reconocimiento de derechos políticos y restitución de tierras.

El último capítulo temático de esta publicación plantea la necesidad de una mirada feminista decolonial para abordar la realidad de las mujeres mapuche. Expone diversas experiencias de organización de mujeres mapuche en contexto de crisis social. Basadas en relatos de mujeres, las autoras relevan la importancia de la organización comunitaria, de una economía local alternativa y del fortalecimiento del tejido social para la protección de los derechos de las mujeres antes las arremetidas de la violencia extractivita y patriarcal. Finalmente, el libro cierra con dos balances del año y del proceso político desplegado: uno desarrollado desde la perspectiva mapuche y el otro desde la perspectiva chilena. Ambos balances, desde enfoques críticos, destacan la complejidad política de traducir la movilización telúrica del 2019 en una nueva relación entre el Estado chileno y el Pueblo Mapuche. Si bien gran parte de esta publicación destaca la dimensión institucional del conflicto, estos capítulos de balance son particularmente iluminadores respecto a los desafíos aún pendientes del proceso decolonizador en curso y el trasfondo ideológico de un conflicto con profundas raíces históricas y, por cierto, también culturales.

Los capítulos que componen este libro aportan miradas críticas que reconocen en el Estallido una oportunidad política para el movimiento mapuche, pero también profundos retos. Es que, ciertamente, para que las oportunidades se traduzcan en impacto efectivo, deben primero interpretarse como tal, para luego ser aprovechadas y canalizadas estratégicamente como recursos transformadores en el sistema político. Y es precisamente la proyección política del Estallido la que plantea desafíos mayúsculos para las organizaciones populares chilenas y mapuche movilizadas. Por un lado, se destacan los retos propios del movimiento mapuche y popular chileno, respecto a su fortalecimiento interno y a una potencial articulación entre sí. Y por otro, se alerta sobre las trabas institucionales — jurídicas, pero también políticas - para la construcción de una nueva relación entre Estado y Pueblo Mapuche, basada en el reconocimiento y los derechos colectivos del territorio. Vale identificar aquí a la propia clase política actual como "enclave autoritario" aún remanente y a la ideología colonial que encarna, como una amenaza y potencial cortapisa para la consagración de la democracia de justicia y dignidad demandada en las calles y comunidades.

Si algo ha quedado demostrado con el Estallido, tal como lo planteó Alvarado Lincopi en el prólogo el número anterior, es que el debate propuesto hace décadas por el movimiento mapuche acerca del modelo político administrativo y la democracia, hoy se ha abierto y ha escalado territorial y políticamente. Esto evidencia, una vez más, que el impacto del movimiento mapuche no se reduce a su demostrada capacidad de resistencia-disrupción ni al 
control territorial, pues también se expresa en su efecto democratizador y decolonizador en la discusión pública. Así mismo, el Estallido ha gatillado procesos de deconstrucción identitaria e intersubjetiva invaluables entre los actores implicados que, aun cuando hoy podrían parecer aspectos meramente folclóricos y pintorescos, a la postre podrían redundar en nuevas formas de militancia y reordenamiento de las solidaridades movilizadas. El espiral de oportunidades políticas desatado por el Estallido está en curso y las ventanas de transformación aún abiertas. Las demandas mapuche se han difundido a nuevos actores y escalado a nuevos territorios donde, no solo se han realineados los discursos y los actores, sino además, se ha agotado la tolerancia a la violencia y la injusticia propias de la ilegítima institucionalidad vigente.

Creemos que esta nueva publicación, en complemento con el número anterior y con nuestro libro "Mitos chilenos sobre el Pueblo Mapuche" (Ediciones UAH, 2019), contribuye a una comprensión históricamente fundamentada de la conflictividad social en Chile y en Wallmapu. Enfatiza el carácter dinámico del conflicto, sin desconocer su larga data, así como también destaca la importancia de las realidades locales y sus actores, sin desestimar la raíz estructural de las violencias que aquejan al territorio. Estudiar y documentar la interacción entre los actores implicados y los hitos que definen el curso del conflicto, nos parece una tarea ineludible para aportarle realismo y menos romanticismo y épica al estudio de una lucha histórica que no lo necesita. El Pueblo Mapuche hoy es sobreviviente de diversas invasiones y despojos territoriales, y esta resistencia es producto de actores y organizaciones concretas que se movilizan activa e interactivamente contra otros acto- res, instituciones y violencias presentes en el territorio. Así mismo, los costos sociales y humanos, del conflicto y la represión no son el simple efecto marginal de la crisis institucional, sino resultado de interacciones entre los actores y las autoridades implicadas. En esta perspectiva es que esta colección presta particular atención a la dimensión dinámica, local y relacional de la contienda.

Continuaremos trabajando en esta colección tal como el Observatorio del Conflicto Social de la Universitat de Barcelona lo hace con su anuario mundial del conflicto, desde hace una década, apostando así por la acumulación de un conocimiento de utilidad para que quienes se movilicen y trabajen por un nuevo marco de relacionamiento entre los poderes del Estado y el territorio mapuche. Confiamos en que la evidencia histórica condensada y sistematizada contribuirá al cambio de rumbo y logrará, a la postre, disuadir a quienes abogan por continuar reprimiendo y convirtiendo —-más allá de la caricatura ${ }^{4}$ - a Wallmapu en el "Vietnam" de un Estado chileno reincidente y obstinado en una solución violenta de un conflicto que demanda a gritos una nueva política. En sociedades cada vez más diversas, el conflicto social jamás se podrá descartar o anular, pero sí canalizarse para que sea dinamizador de los territorios y no aniquilador de las oportunidades vitales y de la 
diversidad ecosistémica.

Mientras editamos este libro en plena crisis pandémica — que abordaremos, junto al proceso constituyente, en el próximo número-, se ha potenciado la militarización y la exclusión en territorio mapuche. No obstante, también y, por sobre todo, se ha visibilizado la capacidad que, como pueblo, los mapuche han desarrollado históricamente para ejercer la autonomía y el autocuidado comunitario y, en la práctica, para autosustentar su vida. La sabiduría mapuche y su medicina, como también sus tradiciones e instituciones políticas, se mantienen activas y cada vez más necesarias en un territorio donde el Estado chileno no es garante del bienestar, en particular de la salud y de la pacífica convivencia. Ciertamente, el dinamismo y vigencia del conflicto nos anima a desarrollar esta colección anual, y a invitar a las y los lectores a una buena y crítica lectura.

4 https://www.biobiochile.cl/noticias/nacional/chile/2020/08/10/diputado-rn-borro-foto-vinculaba-la-cam-trampa-delviet-cong-araucania-vietnam.shtml 